\title{
The relationship between physical activity, appetite and energy intake in older adults: a systematic review
}

Article

Accepted Version

Creative Commons: Attribution-Noncommercial-No Derivative Works 4.0

Clegg, M. E. and Godfrey, A. (2018) The relationship between physical activity, appetite and energy intake in older adults: a systematic review. Appetite, 128. pp. 145-151. ISSN 01956663 doi: https://doi.org/10.1016/j.appet.2018.05.139 Available at https://centaur.reading.ac.uk/80385/

It is advisable to refer to the publisher's version if you intend to cite from the work. See Guidance on citing.

Published version at: https://www.ncbi.nlm.nih.gov/pubmed/29885385

To link to this article DOI: http://dx.doi.org/10.1016/j.appet.2018.05.139

Publisher: Elsevier

All outputs in CentAUR are protected by Intellectual Property Rights law, including copyright law. Copyright and IPR is retained by the creators or other copyright holders. Terms and conditions for use of this material are defined in the End User Agreement.

www.reading.ac.uk/centaur

\section{CentAUR}


Central Archive at the University of Reading

Reading's research outputs online 
The relationship between physical activity, appetite and energy intake in older adults: A systematic review

Clegg, M. $\mathrm{E}^{1}$ and Godfrey, $\mathrm{A}^{2}$

${ }^{1}$ Department of Sport and Health Sciences, Faculty of Health and Life Sciences, Oxford Brookes University, Gipsy Lane, Oxford OX3 0BP

${ }^{2}$ Department of Computer and Information Science, Northumbria University, Newcastleupon-Tyne, NE2 1XE

Corresponding author:

Dr Miriam Clegg

Department of Sport and Health Sciences, Faculty of Health and Life Sciences, Oxford Brookes University, Gipsy Lane, Oxford OX3 0BP

Email: $\underline{\text { mclegg@brookes.ac.uk }}$

Ph: 01865484365

Running title: physical activity, appetite and energy intake in older adults 


\begin{abstract}
Ageing often causes a reduction in appetite and energy intake in older adults which can result in malnutrition. Current guidelines for older adults suggest increasing physical activity to enhance appetite. However, it is unclear if there is evidence to support this advice. This aim of this review is to assess if appetite and energy intake is changed in older adults that undertake acute or regular physical activity (measured from cross sectional and intervention studies). Databases SPORTDiscus, CINAHL, MEDLINE were searched for studies between 1970 and 2017 using search terms related to ageing, physical activity (including exercise), energy and appetite. Studies included contained adults over 60 years, including acute, crosssectional and intervention (longitudinal) studies. Of 34 full-text articles assessed, 8 were included. The Cochrane Collaboration's tool was used for assessing risk of bias. No acute studies were found. Of the cross-sectional studies, one study suggested that individuals who undertake habitual physical activity had an increased energy intake and none of the studies found differences in appetite ratings. Energy intakes increased in the intervention studies, though not always sufficiently to maintain energy balance. One study showed that ability to correctly compensate for previous energy intake was better in those that undertake habitual physical activity. The limited number of studies, wide range of data collection methodologies, time-scales and interventions mean that definitive outcomes are difficult to identify. At this stage advice to increase acute or habitual physical activity as a mean to increase appetite is not supported by sufficient evidence.
\end{abstract}

PROSPERO database (registration number CRD42017058355)

Keywords: Physical activity; appetite; older adults; energy intake; ageing 


\section{Introduction}

Age related loss of appetite can be due to numerous factors, including reduced physical activity and lower metabolic rate. If this reduction in appetite is not compensated for in the long term, it can lead to weight loss and malnutrition. [1]. Middle age is often associated with an increase in body weight and increased rates of obesity and being overweight [2]. However as people age further, both lean body mass and percentage body fat decrease as shown in both cross sectional $[3 ; 4]$ and longitudinal studies $[5 ; 6]$. This is due to a linear decrease in energy intake across the lifespan caused by a lack of appetite and desire to eat [7; 8]. Insufficient energy intake is an important issue and one of the main reasons for malnutrition in older adults [9] who currently fail to meet the estimated average requirements for energy intake [10].

Reduced appetite in older individuals has been documented across a number of satiety studies. Clarkston et al [11] reported that after an overnight fast, older adults tended to be less hungry than their younger counterparts and after a standard meal, older adults reported a greater degree of satiation than younger adults. Rolls et al [12] found that healthy older adults ingested less energy than younger men over a single meal, and older men were subjectively less hungry and more full at the start of lunch. One potential mechanism causing decreases in appetite is a delayed gastric emptying (GE) often seen with advancing years. Most but not all studies suggest that the rate of GE and gastrointestinal transit slows in older compared with younger adults $[13 ; 14 ; 15]$. The rate of GE will affect both the gastric distension signalling fullness via the vagus nerve [16] and the delivery of nutrients initiating satiety via release of satiety hormones [17], indicating that slower GE would result in the stomach remaining distended for a longer period of time and satiety being maintained. It has also been shown in younger and older adults that GE is accelerated in those that undertake habitual physical activity $[18 ; 19]$. Hence it seems appropriate that increasing physical activity may be a potential non-invasive opportunity by which appetite could be increased or maintained in older adults possibly through increasing rates of GE.

In a recent systematic review it has been proposed that habitual physical activity improves appetite control in younger adults but the effect in older individuals is less clear [20]. Current guidelines being produced by organisations such as the NHS and Age UK for older adults 
who are concerned about a reduction in their appetite, recommend increasing their physical activity levels $[21 ; 22]$. Although physical activity is recommended to increase appetite, the type and quantity of physical activity and whether there is evidence available to support this guidance is not clear. The benefit of physical activity in older adults cannot be understated. It has been shown to reduce risk of all-cause mortality, chronic disease, and premature death [23]. However, evidence for increasing appetite with acute or habitual physical activity in older adults appears to be unclear.

Therefore, the aim of this review is to assess if there is evidence to support advice to undertake physical activity as a means of increasing appetite in older adults, where physical activity is defined here as "any bodily movement produced by skeletal muscles that requires energy expenditure" $[24 ; 25]$. Specifically, the objectives are to examine if

(i) regular, habitual physical activity (from cross sectional studied) can influence appetite and energy intake and endocrine measures linked to appetite,

(ii) either acute or long term physical activity interventions can change energy intake and appetite or alter endocrine measures linked to appetite in older individuals.

\section{Materials and methods}

This systematic review followed the Preferred Reporting Items for Systematic Reviews and Meta-Analysis (PRISMA) guidelines [26] and is registered in the PROSPERO database (registration number CRD42017058355).

\section{Search strategy}

The databases SPORTDiscus, CINAHL, MEDLINE were searched for studies between January 1970 and December 2017 comprising of all human participants using the strategy (physical activity AND ageing AND (appetite AND (energy intake OR endocrine measures))). Previous systematic reviews were screened to identify relevant subject headings and key words to include within each subject category. The specific key words used for the search are listed in Table 1.

\section{Inclusion and exclusion criteria}

Limits were set to include articles published in the English language and studies conducted in human adults aged 60+ years. Studies were included if they examined the relationship between either appetite or appetite control or energy intake and being physically active or 
inactive. This includes acute studies looking at single physical activity sessions and appetite, longitudinal studies assessing appetite control before and after a physical activity based intervention in previously inactive individuals and cross sectional studies looking at the relationship between physical activity levels and appetite. Given the limited data on the topic, the decision was taken to include studies involving both residential and community-based individuals.

\section{Data screening and extraction}

Two independent investigators (MC and $\mathrm{AG}$ ) reviewed studies using a systematic hierarchy of exclusion criteria (Figure 1). Records were initially screened for duplicates and these were removed. Record titles were then screened and titles that did not contain reference to energy intake, appetite or physical activity were removed. Record titles that clearly indicated it was a review paper or indicated that it was in an animal, children adolescents or young adults were excluded at this stage.

One author extracted the following information into a spreadsheet: authors, date of publication, sample size, participant characteristics (age, sex, body mass index [BMI], any physical activity details), study setting, physical activity measure, appetite outcome measures and results.

\section{Quality checks}

The Cochrane Collaboration's tool for assessing risk of bias was used to assess selection bias, performance bias, detection bias, attrition bias, reporting bias as well as other bias that may exist in the selected studies [27]. Study inclusion was not influenced by the results of the risk of bias assessment.

\section{Results}

The database search yielded 261 articles and a further 5 were identified from reference lists.

Of these, 31 were eliminated as duplicates and a further 201 based on title and abstract screening. Full text was retrieved for 34 articles, of which 8 satisfied the inclusion criteria. Figure 1 illustrates the systematic review flow diagram. 
Studies were conducted in the US $[28 ; 29 ; 30 ; 31 ; 32 ; 33]$, the Netherlands [34] and Denmark [35]. Participants were aged 70.6 \pm 1.4 years and had a BMI of $25.3 \pm 0.7 \mathrm{~kg} \cdot \mathrm{m}^{2}$ and included 297 males and 380 females.

Three of the studies were cross sectional comparing trained and untrained groups [28; 29; 32], one was a cross sectional cohort study [33]. Two of the studies were randomised control intervention trials $[30 ; 34]$ and two were intervention trials with no control group $[31 ; 35]$. No acute studies were found during literature searching.

\section{Physical activity descriptive}

Physical activity was defined in a variety of different ways depending both on the type of the study (cross sectional versus intervention) (Electronic Supplementary Material Appendix S1).

\section{Cross sectional}

One cross sectional study examined individuals that had been resistance training $\geq 2$ times per week for at least 6 months [29]. The other cross sectional study, by some members of the same research group, was based on requiring specific thresholds in both $\mathrm{VO}_{2 \max }$ and estimated weekly energy expenditure from activity [28]. In the Van Walleghen et al. [32] study, physically active subjects spent $\geq 150 \mathrm{~min} /$ week engaged in self-reported moderate and/or vigorous physical activity for $\geq 2$ years. In the cohort study by Shahar et al. [33], physical activity was calculated from measuring total energy expenditure from doubly labelled water subtracting resting metabolic rate from indirect calorimetry and thermic effect of meals. Activity energy expenditure was then divided into tertiles.

\section{Intervention}

Four studies were intervention trials, one based on gradually increasing moderate intensity physical activity twice per week for 45 min for 17 weeks. Emphasis was placed on skills training to develop muscle strength, coordination, flexibility, speed and endurance. All were trained using activities such as walking, stooping and chair stands, thereby aiming to improve performance of daily pursuits [34]. Another was a resistance training intervention [30] consisting of high intensity progressive resistance training activities for the hip and knee extensors lasting 45mins for 3 days/week over 10 weeks. These two studies also had a nutrition arm and a combined nutrition and physical activity arm. 
In Poehlman and Danworth [31], the cycling activity consisted of cycling 3 times/week for 8 weeks. Prior to each session 10 min of flexibility exercises were completed followed by cycling at $60 \% \mathrm{VO}_{2 \max }$ to expend $150 \mathrm{kcal}$. This increased during the 8 weeks to $85 \%$ of their $\mathrm{VO}_{2 \max }$ and expending $300 \mathrm{kcal}$ per session. In Rosenkilde et al. [35] a 14-day cycling trip with a total distance of $2706 \mathrm{~km}$ was monitored with the cyclists undertaking $193 \pm 10$ $\mathrm{km} /$ day. Both studies had no control group.

\section{Measurements}

\section{Appetite measures}

Appetite measures varied in the studies (Table 2). Appetite measures consisted of appetite questionnaires on a 13-point category scale [28; 29], 5 point Likert scale [33; 34], visual analogue scales. Energy intake measures consisted of 24 hour food records [28], 3 day food records $[30 ; 31 ; 34]$, food frequency questionnaire [33], total energy intake during the cycle [35] and energy intake at an ad libitum meal [29; 32].

\section{Endocrine measures}

Endocrine measures that have been linked to appetite were also measured in some studies including total ghrelin, glucagon-like peptide- 1 (GLP-1) [29; 35], CCK [29], insulin [29; 31; 32; 35], PYY3-36 and plasma leptin [35].

\section{Outcome}

\section{Cross sectional}

In the cross sectional studies there was no effect of having a higher $\mathrm{VO}_{2 \max }$ [28] or resistance training [29] or self-reported physical activity [32] on appetite responses and no difference in energy intake [28], ad libitum energy intake [29; 32], postprandial ghrelin, GLP-1 [29; 32] or insulin [29; 32]. In Apolzan et al, [29] the resistance training group had a higher fasting and postprandial plasma levels of the satiety hormone cholecystokinin. However, in Shahar et al. [33] energy intake and the prevalence of good appetite was higher and fewer participants reported that they did not enjoy their meals in the highest tertile of Daily Activity Energy Expenditure (DAEE). Energy intake regulation over the course of a day was also more accurate in active vs sedentary adults in the Van Walleghen study [32].

\section{Intervention}


Over 17 weeks, a skills-based activity intervention showed no effect on perceived appetite. However the physical activity increased energy intake and carbohydrate intake compared with those not undertaking physical activity [34]. During a resistance training activity intervention, energy intake was reduced in the control and supplement groups, however the physical activity intervention caused less of a decrease in energy intake during the study. And total energy intake was significantly increased in the group receiving both supplement and physical activity [30]. Poehlman and Danforth [31] found energy intake from food diaries increased in 18 of 19 individuals with no change in plasma insulin. In contrast, Rosenkilde et al. [35] found fasting concentrations of insulin, GLP-1, and PYY3-36 increased and fasting leptin and ghrelin remained unchanged, although fasting ghrelin concentrations were lower in 5 of 6 subjects after cycling. Ratings of hunger increased in the evening and morning and ratings of fullness decreased in the evening. Net energy balance was negative.

\section{Discussion}

Current guidelines suggest that older adults who are concerned about a reduction in their appetite should increase their physical activity levels [21;22]. This systematic review aimed to assess if either regular, habitual physical activity or physical activity interventions can influence appetite and energy intake and endocrine measures linked to appetite. However, the limited number of studies and the wide range of time-scales and interventions mean that definite outcomes are difficult to identify, indicating that at this stage these guidelines are not supported by sufficient evidence.

Four cross sectional studies were identified that compared groups of individuals that were either trained or untrained. All except one study found no difference in the appetite or energy intake [33] between groups. One of the studies [32] found that energy intake regulation over the course of a day was more accurate. Meaning that individuals who participated in physical activity were better at compensating for their previous food intake, but that acute energy intake (an ad libitum meal) regulation is impaired in older adults, which is not attenuated by physical activity status. However, this contradicts work by Flint et al. [36]. Their findings suggest that non-obese young and older adults of the same sex, BMI and physical activity level had a similar energy intake despite a significant age difference. Hence, it is possible that once declining physical activity levels in older adults are accounted for [37] there may be no differences between energy intakes in younger and older adults. One of the cross sectional studies included in this review [28] supports this point further. The study found that although 
older subjects had lower mean hunger and desire to eat responses and lower peak hunger and desire to eat, when adjusted for $\mathrm{VO}_{2 \max }$, the mean hunger and desire to eat relationships for age remained significant, but the peak hunger and desire to eat responses were no longer significantly different for age. As age increases, the number of hours of physical activity decreases, as does their description of their appetite as 'average' or 'poor' [38]. Flint et al. [36] speculated that if older adults were to remain as active as they were when younger, they would not have any age-related reduction in appetite, though reductions in appetite due to illness and medication may still exist [39]. Cross sectional studies however can only provide limited evidence.

To date only four intervention studies have taken place, two were based on resistance and skills training and the others did not have a control group. All the intervention studies included in this review demonstrated increases in energy intake, though not all of the physical activity resulted in sufficient energy intake to compensate for the increase in energy expenditure associated with the activity [35]. It is interesting to note that none of the interventions met with or tried to meet the current UK guidelines for physical activity. Current UK guidelines state that older individuals should be undertaking moderate-intensity aerobic physical activity for at least 150 minutes/week; or in vigorous-intensity activity for 75 minutes/week as well as muscle strengthening activities involving the major muscle groups of the body on two or more days per week [40]. Only Rosenkilde et al [35] exceeded this in terms of amount of time spent in moderate/vigorous activity as the participants under took a 14-d cycling trip at a distance of $2706 \mathrm{~km}$.

We hypothesised that energy intake might be increased in those that undertake regularly physical activity due to accelerated GE. This is based on research in habitually active younger adults by Horner et al. [18] and in older adults in Shimamoto et al. [19]. However, in Horner et al. [18] active was defined as undertaking four or more structured exercise sessions per week, where one exercise session was defined as at least 40 min of moderate to high intensity activity. Three of the four intervention studies in this review did not undertake as much physical activity as Horner et al [18] as they were based on resistance training [30] or a skills based activity session [34]. Another used a physical activity intervention that involved cycling $2706 \mathrm{~km}$ over 14 days, which is impractical for the majority of older adults, and resulted in a negative energy balance [35]. The final study [31] provided a physical activity intervention (cycling 3 times per week a stationary bike) that was more realistic but still did 
not meet recommended guidelines [40]. The research by Horner et al. [18] indicates that prescribed exercise may increase appetite by accelerating GE, however the research in older adults was unclear about how much activity was undertaken by the active elderly group [19]. Conversely research in cyclists versus untrained individuals (aged 18-30 years) found no differences between groups [41] indicating that other mechanisms such as lean body mass may need to be investigated [42].

As outlined in the introduction, the physiological benefits of physical activity to older adults are numerous. One potential benefit is the increase or maintenance of muscle mass [43]. Resting metabolic rate has been shown to predict energy intake and hunger, with resting metabolic rate being primarily determined by fat-free mass [44; 45]. Hence increases or maintenance of muscle mass may have implications for energy intake. Other potential mechanisms by which habitual physical activity may increase food intake could be by providing a social outlet for older adults. It is known that loneliness is one of the key factors causing decreased food intake in older adults $[46 ; 47]$. Hence if physical activity is performed habitually in a social context it potentially has the ability to help decrease loneliness.

This systematic review was limited by the number of studies available. Although a large number of studies collect data on both physical activity and food intake, the majority do not compare the relationship between the two. The physical activity used in the reviewed studies varied considerably, and none of the studies looked at the effect of acute physical activity on appetite, suggesting a potential area for further research. Measurement of appetite and energy intake was via a variety of methods. They included 24 hour food records, 3 days food records and food frequency questionnaires all of which are indirect measures of food intake and have been shown to have limitations, particularly in the elderly, who may have diminished functional ability and a reduction in short term memory [48]. Only two studies used measurements of ad libitum food intake in a controlled laboratory environment which made it harder to draw conclusions from the data and suggests the need for more clinical trials using accurate measures of food intake. The heterogeneity of the study cohorts and range of intervention details are also factors, with the inclusion of frail individuals and interventions including intense endurance activities making it hard to make definitive recommendations. 


\section{Conclusions}

This systematic review indicates that there is no sufficient evidence currently available to support the advice that physical activity may attenuate the decrease in appetite and energy intake that occurs due to ageing. However there are many benefits associated with physical activity including increasing lean body mass and increasing resting metabolic rate [23] which are positively associated with appetite $[49 ; 50]$. This review calls for further placebo controlled, clinical intervention trials using guideline physical activity goals and incorporating a complete spectrum of the satiety measures and direct measures of food intake.

\section{Financial support}

This research was supported by an Oxford Brookes University Research Excellence Award. Oxford Brookes University had no role in the design, analysis or writing of this article.

\section{Conflict of interest}

There are no conflicts of interest associated with this paper. 


\section{References}

1. Morley JE, Silver AJ (1988) Anorexia in the elderly. Neurobiol Aging 9, 9-16.

2. Health and Social Care Information Centre. Health Survey for England - 2014.

https://www.gov.uk/government/statistics/health-survey-for-england-2014 (accessed 25 July 17

3. Silver AJ, Guillen CP, Kahl MJ, Morley JE (1993) Effect of aging on body fat. Journal of the American Geriatrics Society 41, 211-213.

4. Kuskowska-Wolk A, Rossner S (1990) Prevalence of obesity in Sweden: cross-sectional study of a representative adult population. J Intern Med 227, 241-246.

5. Chumlea WC, Garry PJ, Hunt WC, Rhyne RL (1988) Distributions of serial changes in stature and weight in a healthy elderly population. Hum Biol 60, 917-925.

6. Genton L, Karsegard VL, Chevalley T, Kossovsky MP, Darmon P, Pichard C (2011) Body composition changes over 9 years in healthy elderly subjects and impact of physical activity.

Clin Nutr 30, 436-442.

7. Hallfrisch J, Muller D, Drinkwater D, Tobin J, Andres R (1990) Continuing diet trends in men: the Baltimore Longitudinal Study of Aging (1961-1987). J Gerontol 45, M186-191.

8. Sjogren A, Osterberg T, Steen B (1994) Intake of energy, nutrients and food items in a tenyear cohort comparison and in a six-year longitudinal perspective: a population study of 70and 76-year-old Swedish people. Age Ageing 23, 108-112.

9. de Groot LC, Verheijden MW, de Henauw S, Schroll M, van Staveren WA, Investigators S (2004) Lifestyle, nutritional status, health, and mortality in elderly people across Europe: a review of the longitudinal results of the SENECA study. The journals of gerontology $\mathbf{5 9}$, $1277-1284$.

10. Public Health England. (2016) National Diet and Nutrition Survey: Results from Years 5 and 6 (Combined) of the Rolling Programme (2012/2013-2013/2014). London, UK.

11. Clarkston WK, Pantano MM, Morley JE, Horowitz M, Littlefield JM, Burton FR (1997) Evidence for the anorexia of aging: gastrointestinal transit and hunger in healthy elderly vs. young adults. Am J Physiol 272, R243-248.

12. Rolls BJ, Dimeo KA, Shide DJ (1995) Age-related impairments in the regulation of food intake. The American journal of clinical nutrition 62, 923-931.

13. Horowitz M, Maddern GJ, Chatterton BE, Collins PJ, Harding PE, Shearman DJ (1984) Changes in gastric emptying rates with age. Clin Sci (Lond) 67, 213-218. 
14. Moore JG, Tweedy C, Christian PE, Datz FL (1983) Effect of age on gastric emptying of liquid--solid meals in man. Dig Dis Sci 28, 340-344.

15. Wegener M, Borsch G, Schaffstein J, Luth I, Rickels R, Ricken D (1988) Effect of ageing on the gastro-intestinal transit of a lactulose-supplemented mixed solid-liquid meal in humans. Digestion 39, 40-46.

16. Geliebter A (1988) Gastric distension and gastric capacity in relation to food intake in humans. Physiol Behav 44, 665-668.

17. Moran TH, McHugh PR (1982) Cholecystokinin suppresses food intake by inhibiting gastric emptying. Am J Physiol 242, R491-497.

18. Horner KM, Byrne NM, Cleghorn GJ, King NA (2015) Influence of habitual physical activity on gastric emptying in healthy males and relationships with body composition and energy expenditure. The British journal of nutrition 114, 489-496.

19. Shimamoto C, Hirata I, Hiraike Y, Takeuchi N, Nomura T, Katsu K (2002) Evaluation of gastric motor activity in the elderly by electrogastrography and the (13)C-acetate breath test.

Gerontology 48, 381-386.

20. Beaulieu K, Hopkins M, Blundell J, Finlayson G (2016) Does Habitual Physical Activity Increase the Sensitivity of the Appetite Control System? A Systematic Review. Sports

Medicine 46, 1897-1919.

21. NHS choices. (2015) Keeping your weight up in later life.

http://www.nhs.uk/Livewell/over60s/Pages/Underweightover60.aspx (accessed 8th August 2017

22. Age UK. (2017) Healthy eating overview - Maintaining a healthy weight.

http://www.ageuk.org.uk/health-wellbeing/healthy-eating-landing/healthy-eatingoverview/maintaining-a-healthy-weight/ (accessed 8th August 2017

23. Mora JC, Valencia WM (2018) Exercise and Older Adults. Clin Geriatr Med 34, 145162.

24. Caspersen CJ, Powell KE, Christenson GM (1985) Physical activity, exercise, and physical fitness: definitions and distinctions for health-related research. Public Health Rep 100, 126-131.

25. WHO. (2017) Health topics-Physical activity.

http://www.who.int/topics/physical_activity/en/ (accessed 28 July 17

26. Moher D, Liberati A, Tetzlaff J, Altman DG, Group P (2010) Preferred reporting items for systematic reviews and meta-analyses: the PRISMA statement. Int J Surg 8, 336-341. 
27. Higgins JPT, Green S (editors) Cochrane Handbook for Systematic Reviews of Interventions Version 5.1.0 [updated March 2011]. , The Cochrane Collaboration, 2011 28. Apolzan JW, Flynn MG, McFarlin BK, Campbell WW (2009) Age and physical activity status effects on appetite and mood state in older humans. Applied Physiology, Nutrition, And Metabolism = Physiologie Appliquée, Nutrition Et Métabolisme 34, 203-211.

29. Apolzan JW, Leidy HJ, Mattes RD, Campbell WW (2011) Effects of food form on food intake and postprandial appetite sensations, glucose and endocrine responses, and energy expenditure in resistance trained v. sedentary older adults. The British Journal Of Nutrition 106, 1107-1116.

30. Fiatarone MA, O'Neill EF, Ryan ND, Clements KM, Solares GR, Nelson ME, Roberts SB, Kehayias JJ, Lipsitz LA, Evans WJ (1994) Exercise training and nutritional supplementation for physical frailty in very elderly people. $N$ Engl J Med 330, 1769-1775. 31. Poehlman ET, Danforth E, Jr. (1991) Endurance training increases metabolic rate and norepinephrine appearance rate in older individuals. Am J Physiol 261, E233-239.

32. Van Walleghen EL, Orr JS, Gentile CL, Davy KP, Davy BM (2007) Habitual physical activity differentially affects acute and short-term energy intake regulation in young and older adults. International Journal Of Obesity (2005) 31, 1277-1285.

33. Shahar DR, Yu B, Houston DK, Kritchevsky SB, Lee JS, Rubin SM, Sellmeyer DE, Tylavsky FA, Harris TB, Health A, Body Composition S (2009) Dietary factors in relation to daily activity energy expenditure and mortality among older adults. J Nutr Health Aging 13, 414-420.

34. de Jong N, Chin APMJM, de Graaf C, van Staveren WA (2000) Effect of dietary supplements and physical exercise on sensory perception, appetite, dietary intake and body weight in frail elderly subjects. British Journal of Nutrition 83, 605-613 609p.

35. Rosenkilde M, Morville T, Andersen PR, Kjær K, Rasmusen H, Holst JJ, Dela F, Westerterp K, Sjödin A, Helge JW (2015) Inability to match energy intake with energy expenditure at sustained near-maximal rates of energy expenditure in older men during a 14-d cycling expedition. The American Journal Of Clinical Nutrition 102, 1398-1405.

36. Flint KMG, Van Walleghen EL, Kealey EH, VonKaenel S, Bessesen DH, Davy BM (2008) Differences in eating behaviors between nonobese, weight stable young and older adults. Eating Behaviors 9, 370-375.

37. Schrack JA, Zipunnikov V, Goldsmith J, Bai J, Simonsick EM, Crainiceanu C, Ferrucci L (2014) Assessing the "physical cliff": detailed quantification of age-related differences in daily patterns of physical activity. The journals of gerontology 69, 973-979. 
38. Nuvoli G (2015) Family meal frequency, weight status and healthy management in children, young adults and seniors. A study in Sardinia, Italy. Appetite 89, 160-166. 39. Morley JE (2001) Decreased food intake with aging. The journals of gerontology $\mathbf{5 6}$ Spec No 2, 81-88.

40. Bull F, and the Expert Working Groups Physical Activity Guidelines in the U.K.: Review and Recommendations. School of Sport, Exercise and Health Sciences, Loughborough University.

41. Rehrer NJ, Beckers E, Brouns F, Hoor ten F, Saris WH (1989) Exercise and training effects on gastric emptying of carbohydrate beverages. Medicine and science in sports and exercise 21, 540-549.

42. Beaulieu K, Hopkins M, Blundell J, Finlayson G (2017) Homeostatic and nonhomeostatic appetite control along the spectrum of physical activity levels: An updated perspective. Physiol Behav.

43. Lopez P, Pinto RS, Radaelli R, Rech A, Grazioli R, Izquierdo M, Cadore EL (2017) Benefits of resistance training in physically frail elderly: a systematic review. Aging Clin Exp Res.

44. Caudwell P, Finlayson G, Gibbons C, Hopkins M, King N, Naslund E, Blundell JE (2013) Resting metabolic rate is associated with hunger, self-determined meal size, and daily energy intake and may represent a marker for appetite. The American journal of clinical nutrition 97, 7-14.

45. Blundell JE, Caudwell P, Gibbons C, Hopkins M, Naslund E, King N, Finlayson G (2012) Role of resting metabolic rate and energy expenditure in hunger and appetite control: a new formulation. Dis Model Mech 5, 608-613.

46. de Castro JM, Stroebele N (2002) Food intake in the real world: implications for nutrition and aging. Clin Geriatr Med 18, 685-697.

47. Clegg ME, Williams EA (2018) Optimizing nutrition in older people. Maturitas 112, 3438.

48. Ortiz-Andrellucchi A, Sanchez-Villegas A, Doreste-Alonso J, de Vries J, de Groot L, Serra-Majem L (2009) Dietary assessment methods for micronutrient intake in elderly people: a systematic review. The British journal of nutrition 102 Suppl 1, S118-149. 49. Hopkins M, Blundell JE (2017) Energy Metabolism and Appetite Control: Separate Roles for Fat-Free Mass and Fat Mass in the Control of Food Intake in Humans. In Appetite and Food Intake: Central Control, 2nd ed. [RBS Harris, editor]. Boca Raton (FL). 
50. Blundell JE, Finlayson G, Gibbons C, Caudwell P, Hopkins M (2015) The biology of appetite control: Do resting metabolic rate and fat-free mass drive energy intake? Physiol Behav 152, 473-478. 


\section{Figure headings:}

Figure 1. Flowchart of methodology used for identifying studies included in the systematic review. 


\section{Tables}

Table 1. Keywords included in database search strategy

\begin{tabular}{|c|c|c|c|c|}
\hline Physical activity & Ageing & Appetite & Energy intake & Endocrine measures \\
\hline Motor activity & Elderly & $\begin{array}{l}\text { Feeding behavior } \\
\text { or food } \\
\text { preferences }\end{array}$ & Diet & Gut peptide \\
\hline Exercise & Older & Hunger & Calori* intake & Peptide YY or PYY \\
\hline $\begin{array}{l}\text { Oxygen } \\
\text { consumption }\end{array}$ & Senescent & Satiety & Food intake & Ghrelin \\
\hline Physical Fitness & Geriatric & Satiation & Meal size & $\begin{array}{l}\text { Glucagon-like } \\
\text { peptide-1 or GLP-1 }\end{array}$ \\
\hline Exercise tolerance & Retired & Fullness & $\begin{array}{l}\text { Energy } \\
\text { compensation }\end{array}$ & $\begin{array}{l}\text { Pancreatic } \\
\text { polypeptide or PP }\end{array}$ \\
\hline Exercise test & & Motivation to eat & Energy density & Leptin \\
\hline $\begin{array}{l}\text { Physical } \\
\text { endurance }\end{array}$ & & Food choice & $\begin{array}{l}\text { Dietary protein or } \\
\text { dietary fat or } \\
\text { dietary } \\
\text { carbohydrate }\end{array}$ & Insulin \\
\hline $\begin{array}{l}\text { Physical } \\
\text { performance }\end{array}$ & & Food selection & Macronutrient & $\begin{array}{l}\text { Cholecystokinin or } \\
\text { CCK }\end{array}$ \\
\hline Aerobic & & Desire to eat & & \\
\hline Aerobic capacity & & Palatability & & \\
\hline Training & & Food reward & & \\
\hline Maximal VO2 & & Hedonic & & \\
\hline Physical capacity & & Liking & & \\
\hline & & Wanting & & \\
\hline
\end{tabular}


Table 2: Appetite related outcome measures and results in the studies included in the systematic review. The studies highlighted in grey indicate intervention studies.

\begin{tabular}{|c|c|c|c|c|}
\hline & Food intake & Ad libitum meal & Appetite rating & Endocrine measures \\
\hline Apolzan et al. (2009) [28] & $\begin{array}{l}24 \text { hour food records } \\
=\end{array}$ & $\mathrm{n} / \mathrm{a}$ & $\begin{array}{l}13 \text { point category scale } \\
=\end{array}$ & $\mathrm{n} / \mathrm{a}$ \\
\hline Apolzan et al (2011) [29] & $\mathrm{n} / \mathrm{a}$ & $\begin{array}{l}\text { ad libitum meal } \\
=\end{array}$ & $\begin{array}{l}13 \text { point category scale } \\
=\end{array}$ & $\begin{array}{l}\mathrm{CCK}+ \\
\text { total ghrelin = } \\
\text { glucagon-like peptide- } 1 \\
(\text { GLP-1) }= \\
\text { insulin }=\end{array}$ \\
\hline De Jong et al (2000) [34] & 3 day food records + & $\mathrm{n} / \mathrm{a}$ & 5 point likert scale $=$ & $\mathrm{n} / \mathrm{a}$ \\
\hline $\begin{array}{l}\text { Fiatarone et al. (1994) } \\
\text { [30] }\end{array}$ & 3 day food records + & $\mathrm{n} / \mathrm{a}$ & $\mathrm{n} / \mathrm{a}$ & $\mathrm{n} / \mathrm{a}$ \\
\hline $\begin{array}{l}\text { Poehlman et al. (1991) } \\
\text { [31] }\end{array}$ & 3 day food records + & $\mathrm{n} / \mathrm{a}$ & $\mathrm{n} / \mathrm{a}$ & Insulin $=$ \\
\hline $\begin{array}{l}\text { Rosenkilde et al. (2015) } \\
\text { [35] }\end{array}$ & $\mathrm{n} / \mathrm{a}$ & $\mathrm{n} / \mathrm{a}$ & visual analogue scales + & $\begin{array}{l}\text { total ghrelin }= \\
\text { glucagon-like peptide- } 1 \\
\text { (GLP-1) }+ \\
\text { PYY3-36 + } \\
\text { Leptin = } \\
\text { insulin + }\end{array}$ \\
\hline Sharar et al. (2009) [33] & $\begin{array}{l}\text { food frequency } \\
\text { questionnaire } \\
+\end{array}$ & $\mathrm{n} / \mathrm{a}$ & $\mathrm{n} / \mathrm{a}$ & $\mathrm{n} / \mathrm{a}$ \\
\hline $\begin{array}{l}\text { Van Walleghen et al. } \\
\text { (2007) [32] }\end{array}$ & $\mathrm{n} / \mathrm{a}$ & $\begin{array}{l}\text { ad libitum meal } \\
=\end{array}$ & $\begin{array}{l}\text { visual analogue scales } \\
=\end{array}$ & Insulin $=$ \\
\hline
\end{tabular}

difference

+indicates it significantly increased

$\mathrm{n} / \mathrm{a}$ indicates that this measure was not collected in this study 